\title{
Hypogonadism And Acute Hepatitis Caused by Ingestion of Epistane (EAST®) For Body-Building Purposes
}

\section{Background}

Self-administration of anabolic/androgenic steroids among bodybuilders is an underestimated problem that is either not admitted, or only reluctantly by patients.

\section{Case presentation}

A 19 year old male (planning to study medicine!) presented with left sided gynaecomastia, general malaise and erectile problems. Investigations revealed acute hepatitis: ALT $2125 \mathrm{U} / \mathrm{L}$ [Ref. range $(\mathrm{RR})<45]$ and hypogonadotropic hypogonadism: $\mathrm{LH}-1.6 \mathrm{IU} / \mathrm{L}$ [RR: 1.5-9.3], testosterone - $0.214 \mathrm{ng} / \mathrm{mL}$ [RR: 2.49-8.36]. Testicular ultrasound was normal. He denied excessive alcohol consumption. Hospital admission was organised.

The patient then reluctantly admitted that he was taking anabolic steroids for at least two months, i.e. EAST ${ }^{\circledR}$ (Enhancing Athletic Sports Technology - Anabolic Technologies Cosmetics, USA), that contains 2a, 3a-epithiol-17a-methyl-17b-hydroxy-5a-androstane (also known as epistane - a substance binding inter alia with androgen receptors), milk thistle - advertised as an antidote for hepatotoxic effect of epistane, N-Acetyl-L-Cysteine and Tongkat Ali (Long Jack Malaysian Ginseng - supposedly improves libido during ingestion of epistane) (Figure 1) as well as BULL $K ®$ - a preparation of vitamins and resveratrol - advertised as an antidote for side-effects of anabolic steroids (Figure 2).

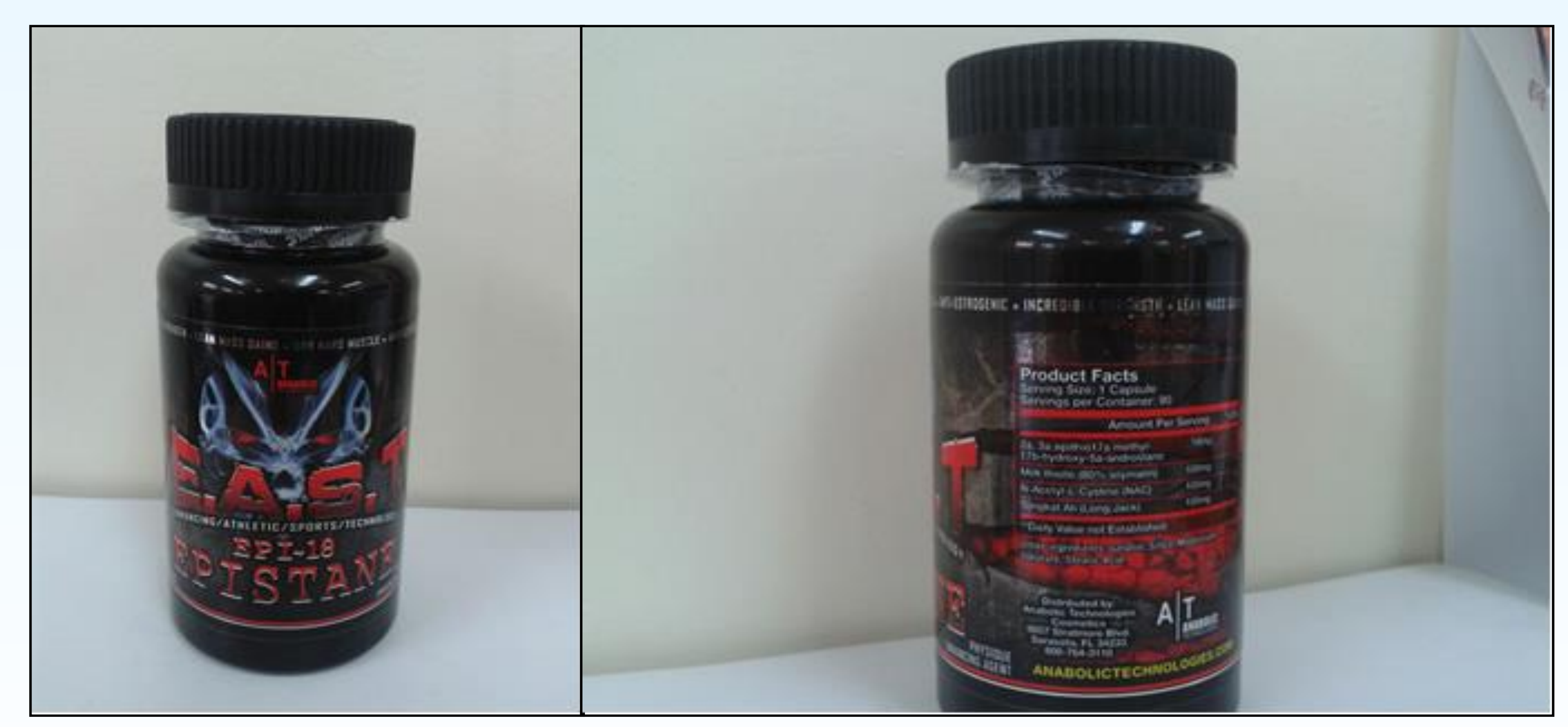

FIGURE 1: $A$ bottle of EAST® containing anabolic steroids that caused acute hepatitis and hypogonadotropic hypogonadism in a 19 year old subject. List of contents presented on the hypogonadorc
right picture.

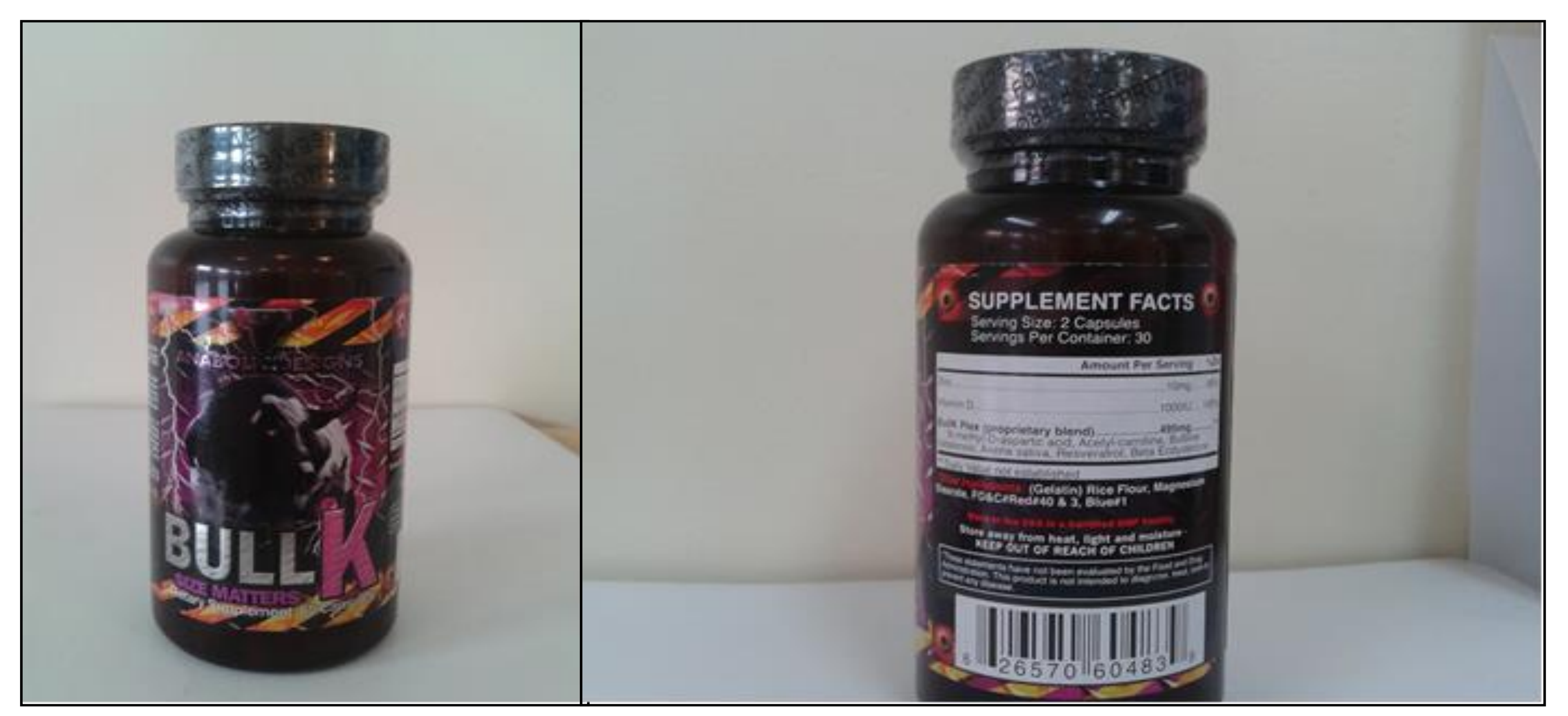

FIGURE 2: A bottle of BULLK® tablets to be taken with EAST®. This was supposed to prevent adverse effects of anabolic steroids contained in the EAST $\circledast$ preparation.

\section{Clinical outcome}

We confirmed markedly reduced testosterone concentrations (0.87 $\mathrm{ng} / \mathrm{mL}$ [RR: 2.49-8.36], LH 2.26 IU/L, FSH $5.95 \mathrm{IU} / \mathrm{L}$ (RR 0.7-11.1)) and liver dysfunction (ALT 252.0 IU/L, AST $113.0 \mathrm{IU} / \mathrm{I}$, RR: 17-59).

$\mathrm{He}$ had normal thyroid functions tests, prolactin $(13.77 \mathrm{ng} / \mathrm{mL}$, RR: 3.9$25.4 \mathrm{ng} / \mathrm{mL}$ ), and morning cortisol $(602 \mathrm{nmol} / \mathrm{L})$.

Viral hepatitis and autoimmune causes of hepatitis were excluded.

Ultrasonography confirmed gynaecomastia without significant abdominal pathology.

Stimulation test revealed satisfactory testosterone response to hCG (2500u im.) - see below:

Total testosterone concentrations before and after hCG:

$0.87 \mathrm{ng} / \mathrm{ml} \rightarrow 2.96$ (two days after $\mathrm{hCG} \rightarrow 4.33 \mathrm{ng} / \mathrm{ml}$ (three days after hCG).

A short course of clomiphene citrate treatment was recommended as well as an outpatient check of liver function tests. The patient, however, failed to attend further follow-up appointments.

\section{Conclusions}

Our case demonstrates severe risks associated with the use of anabolic steroids (acute hepatitis/hypogonadism) that might not be realized by patients who believe that they are taking "antidotes" and fail to follow medical advice.

Unfortunately, apart from dubious "internet fora", there is a paucity of reliable information regarding both the potency, receptor affinity, adverse effects and genuine duration of action of a given compound [1]. Biological activity of a given substance might be markedly different from that claimed by the producer. There is also no clear algorithm regarding most effective treatment of such cases [1].

\section{References:}

1.Karavolos S, Reynolds M, Panagiotopoulou N, et al. Male central hypogonadism secondary to exogenous androgens: a review of the drugs and protocols highlighted by the online community of users for prevention and/or mitigation of adverse effects. Clinical Endocrinology 2015; 82, 624-632 